\title{
DESAFIOS PARA AS METODOLOGIAS BIM NO CONTEXTO DA REABILITAÇÃO ESTRUTURAL: ANÁLISE DE DOIS CASOS DE ESTUDO
}

\author{
Luís Castro $^{(1)}$, João Pedro Silva ${ }^{(1)}$, Fabiana Mendes ${ }^{(1)}$, José Carlos Lino ${ }^{(1)}$ \\ (1) NEWTON - Consultores de Engenharia, Lda. - Porto
}

\begin{abstract}
Resumo
Apesar da crescente implementação BIM no contexto de projeto de Estruturas em Portugal, há ainda desafios importantes a ultrapassar no que diz respeito à realidade da reabilitação estrutural, em particular no que diz respeito a: (i) técnicas, detalhe e verificação do levantamento do existente; (ii) necessidade de classes de objetos adequadas à modelação do existente e de técnicas de reforço. Nesse contexto, o presente artigo aborda a análise dos desafios BIM em dois casos de estudo, em particular a Escola Superior de Música, Artes e Espetáculo no Porto e o Edifício Braamcamp em Lisboa. Em ambos os casos de estudo, não estava disponível um levantamento por nuvem de pontos, tendo sido necessário desenvolver metodologias de trabalho compatíveis com as limitações dos levantamentos existentes. A discussão dos casos de estudo inclui: avaliação da acuidade de levantamentos existentes com base na tentativa de modelação e deteção de incoerências no material disponível, permitindose chegar a soluções finais satisfatórias; modelação de técnicas de ligação entre elementos existentes (paredes de alvenaria de pedra) e novos elementos estruturais (lajes alveolares); modelação de reforço de vigas em betão armado existentes com recurso a encamisamento; definição de zonas a preservar e demolir e respetivo faseamento construtivo.
\end{abstract}

\section{Introdução}

A implementação do BIM (Building Information Modeling) ao nível da reabilitação estrutural, é, cada vez mais, uma realidade no setor da AEC. Esta metodologia, através de um modelo tridimensional dinâmico, permite introduzir diferentes informações das mais variadas especialidades, bem como do encadeamento e faseamento entre as mesmas, resultando num modelo central BIM, fidedigno e atualizado em tempo real, possibilitando a consulta da informação por parte de todos os intervenientes, deteção de eventuais incompatibilidades e resolução das mesmas [1], [2]. Com efeito, resulta num incremento significativo da qualidade do projeto de execução, na diminuição do tempo e custo de conceção, bem como da obtenção de estimativas orçamentais mais fidedignas e próximas da realidade [3].

Em edições anteriores do PTBIM - Congresso Português de Building Information Modeling, foram apresentados artigos relacionados com reabilitação de estruturas recorrendo à 
metodologia BIM, como por exemplo um estudo em que foi aplicado um levantamento estrutural através de laser scanner e das plantas existentes [4]; a reabilitação estrutural com recurso ao BIM de uma forma mais generalizada aplicada a edifícios singulares, enumerando as várias etapas necessárias para a reabilitação dos edifícios em questão [5]; um trabalho onde se realizou um enquadramento da tecnologia laser aplicada à engenharia civil, mecânica, arquitetura, entre outras e também uma recolha de dados através da elaboração de um modelo 3D com recurso a esta mesma metodologia para o controlo da fase construtiva [6]; a exploração do uso em reabilitação de uma grande biblioteca de dados de conhecimento de trabalhos de construção (PRONIC), que abrange o setor de construção de edifícios e de estradas, aliada ao BIM [7].

Sendo esta uma temática recorrente na nossa atualidade, o presente artigo procura dar sequência e complementar o trabalho já desenvolvido em edições anteriores.

Para o efeito, apresentam-se dois casos de estudo, nomeadamente a "Reabilitação estrutural do ESMAE no Porto" e o "Edifício Braamcamp em Lisboa".

No primeiro caso de estudo será abordada uma metodologia de trabalho alternativa ao levantamento estrutural por nuvem de pontos, uma vez que este tipo de tecnologia está frequentemente indisponível não existindo facilidade por parte do dono de obra em assumir esse custo. A abordagem consistiu na compatibilização da informação obtida por várias fontes (fotos, visita ao local, medições, projeto camarário, etc), devidamente integrada no modelo BIM consolidado.

Outro tema abordado, neste caso de estudo, invoca técnicas de modelação para a ligação entre elementos estruturais existentes utilizando reforços por encamisamento em betão, com especial ênfase em aspetos de caracterização geométrica.

Relativamente ao segundo caso de estudo, dá-se um enfoque à possibilidade de modelação explícita dos elementos a reforçar, dos elementos a demolir e dos elementos a manter, com os códigos tradicionalmente utilizados da cor vermelha e amarela, demonstrando a viabilidade e a facilidade com que esta informação pode ser implementada e abordando a questão do faseamento construtivo através do modelo BIM. Para tal, foi efetuada uma análise estrutural do modelo existente, permitindo o cálculo de novos elementos de reforço e posterior modelação dos mesmos.

\section{Reabilitação estrutural da ESMAE no Porto}

Este edifício da ESMAE destina-se ao ensino superior de música e artes do espetáculo, localizado na cidade do Porto e tendo como requerente o Instituto Politécnico do Porto. É constituído por uma estrutura heterogénea com zonas em pórticos e lajes vigadas em betão armado e zonas com paredes resistentes em alvenaria de pedra.

O edifício encontra-se ao serviço de companhias de teatro, mas terá uma intervenção profunda permitindo a utilização como Escola Superior de Música. Nesse sentido percebe-se que a componente acústica teve grande influência nas escolhas estruturais e de materiais, e consequentemente um aumento das cargas sobre a estrutura.

Sendo um edifício com alguma antiguidade foi alvo de uma prospeção estrutural com obtenção de resultados fundamentais para a elaboração de um projeto de reabilitação estrutural. Tendo em conta o relatório referido, optou-se por reaproveitar alguns elementos existentes reforçando- 
os com encamisamentos por betão armado e introduzindo elementos novos, como por exemplo lajes alveolares.

Para dar início ao processo de reabilitação estrutural, acedeu-se a plantas de arquitetura e estruturais em formato digital editável 2D. No entanto, por forma a entender melhor o funcionamento estrutural do edifício e a ligação entre elementos, foi necessária a deslocação ao local por parte da equipa de projeto que recolheu detalhes fundamentais para erguer um modelo BIM de estruturas o mais fidedigno possível, perante a inexistência de um modelo BIM prévio de arquitetura (ver Figura 1).

Para além disso, foram recolhidos e modelados elementos arquitetónicos o que permitiu uma melhor compreensão de todo o funcionamento do edifício.

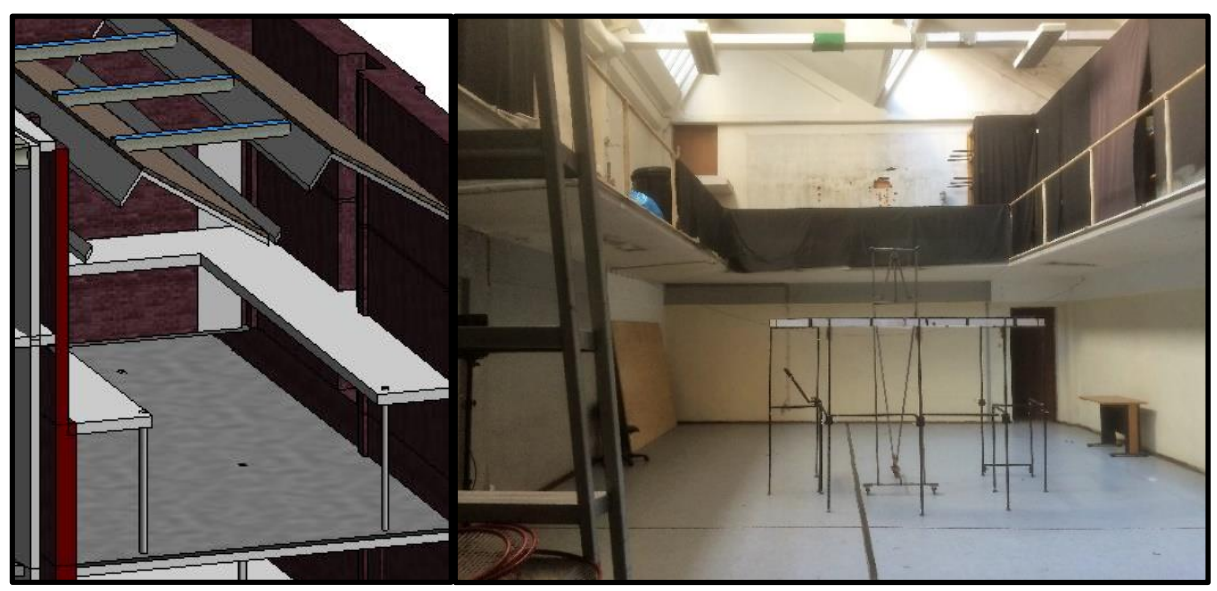

Figura 1: Compatibilização do modelo 3D com a estrutura real.

$\mathrm{Na}$ conceção do modelo 3D, particularmente para o caso das lajes alveolares utilizadas na reabilitação estrutural, foi necessário criar uma nova classe de objetos para este tipo de elementos que não constam na base de dados do software e que são essenciais no modelo BIM. Para este efeito, foram desenvolvidos novos elementos estruturais posteriormente usados no modelo final. Na Figura 2 pode observar-se a ligação entre os novos elementos criados (laje alveolar) e as paredes de alvenaria de pedra do edifício.
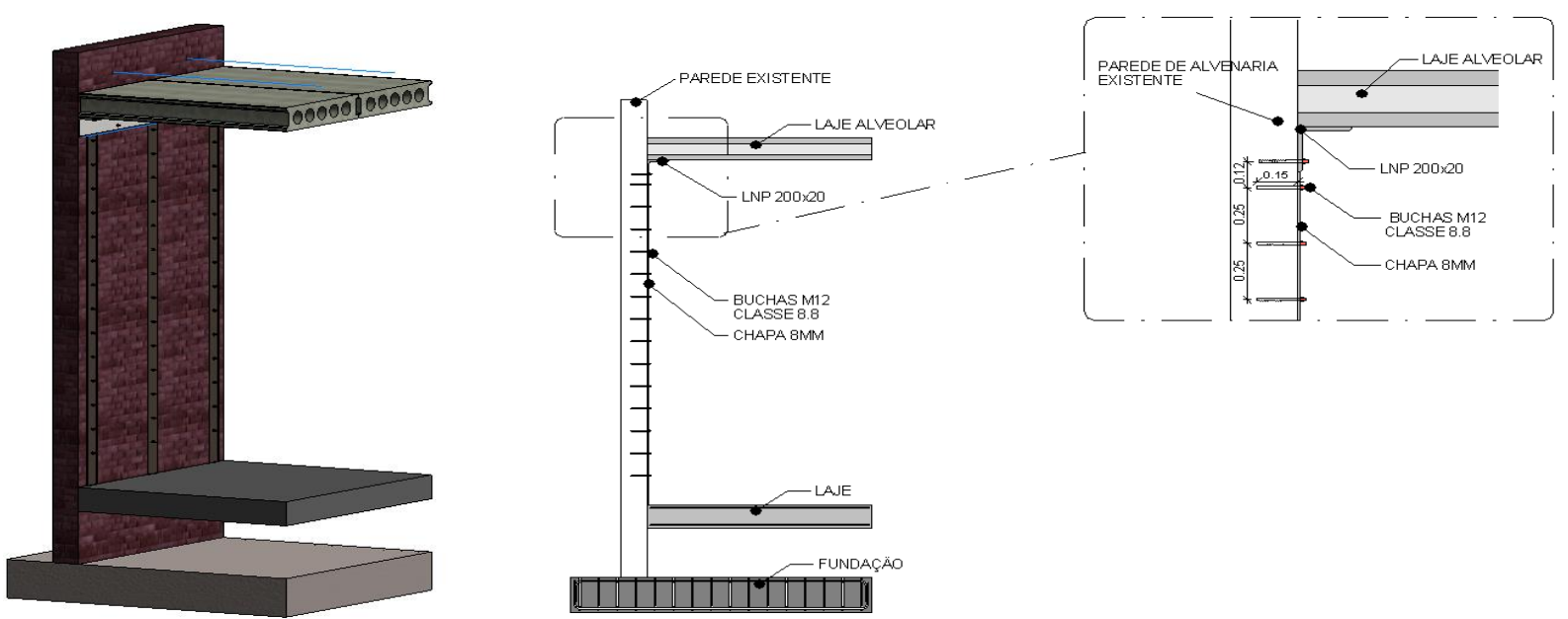

Figura 2: Ligação entre as paredes de alvenaria e as lajes alveolares. 
A realização por parte da NEWTON do modelo BIM foi percecionada pelo próprio gabinete de arquitetura como uma mais-valia que permitiu explicar ao cliente determinados aspetos da obra. Foi solicitada a criação de visualizações avançadas as quais, apesar do modelo não ter sido criado com esse uso em vista, ajudaram o cliente a compreender, não só as soluções de reforço, mas também aspetos arquitetónicos. Na figura 3 apresentam-se duas perspetivas do modelo de estruturas correspondente ao edifício alvo considerado neste caso de estudo (Escola Superior de Música, Artes e Espetáculo no Porto).

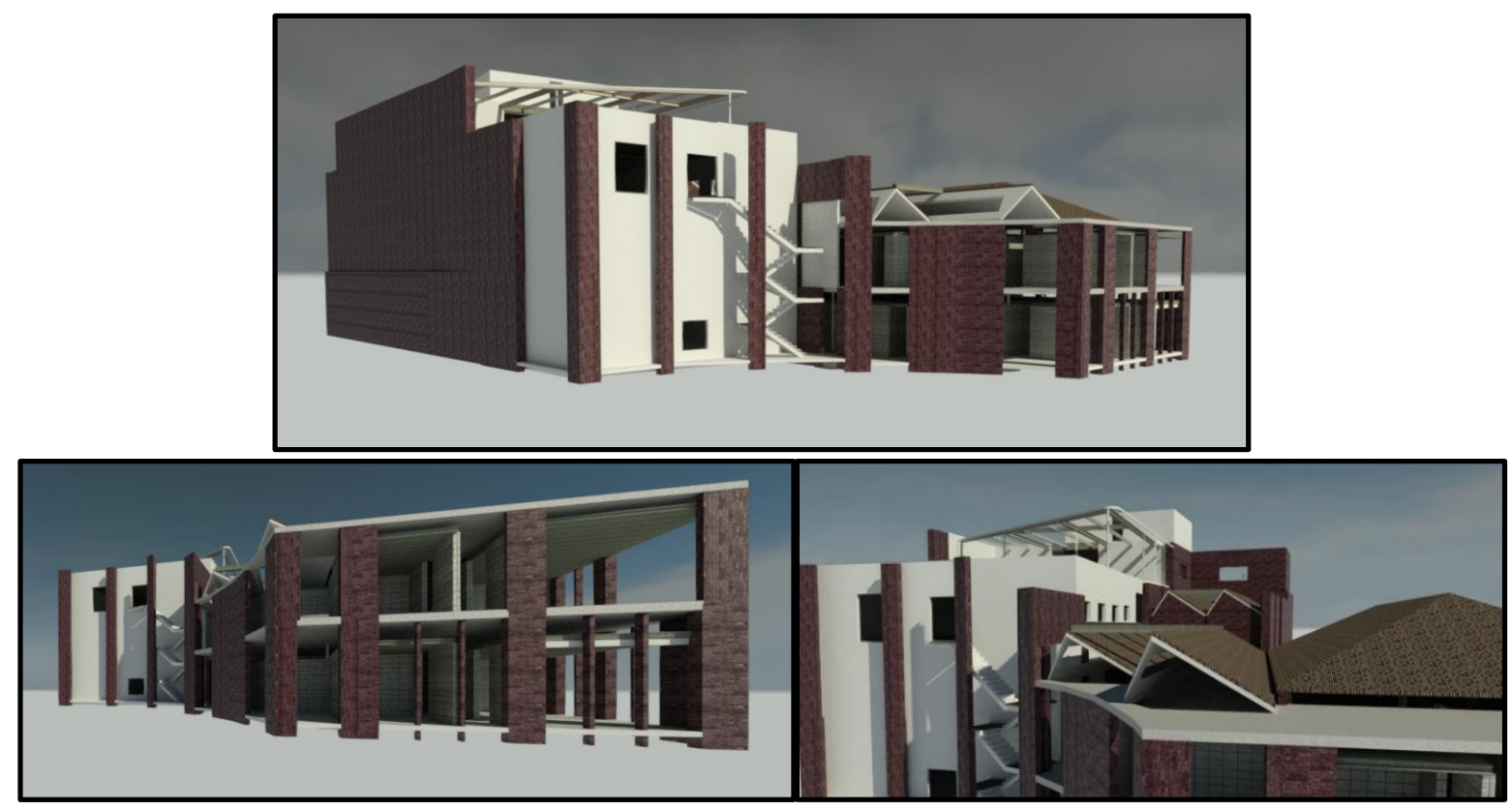

Figura 3: Render do modelo de estruturas concluído.

Após todo o processo de análise estrutural e cálculo, os reforços por encamisamento, armaduras, bem como a identificação dos elementos a demolir, foram adicionadas ao modelo inicial (ver Figura 4). As novas armaduras tiveram a função de reforçar a estrutura de acordo com os novos requisitos de utilização e de fazer a ligação entre os elementos estruturais existentes e os novos elementos.

Nessa mesma figura é também apresentado um exemplo de um reforço de armadura, fazendo a ligação entre o novo elemento estrutural e o elemento existente. Todas estas armaduras correspondem a acréscimos inerentes ao reforço estrutural com cores diferentes para facilitar a sua visualização e compreensão.

A modelação dos reforços estruturais permitiu a visualização de colisões com as armaduras e elementos existentes e um estudo aprofundado e mais exequível de todas as ligações e detalhes necessários para a correta execução em obra bem como uma quantificação mais real dos trabalhos a realizar. 


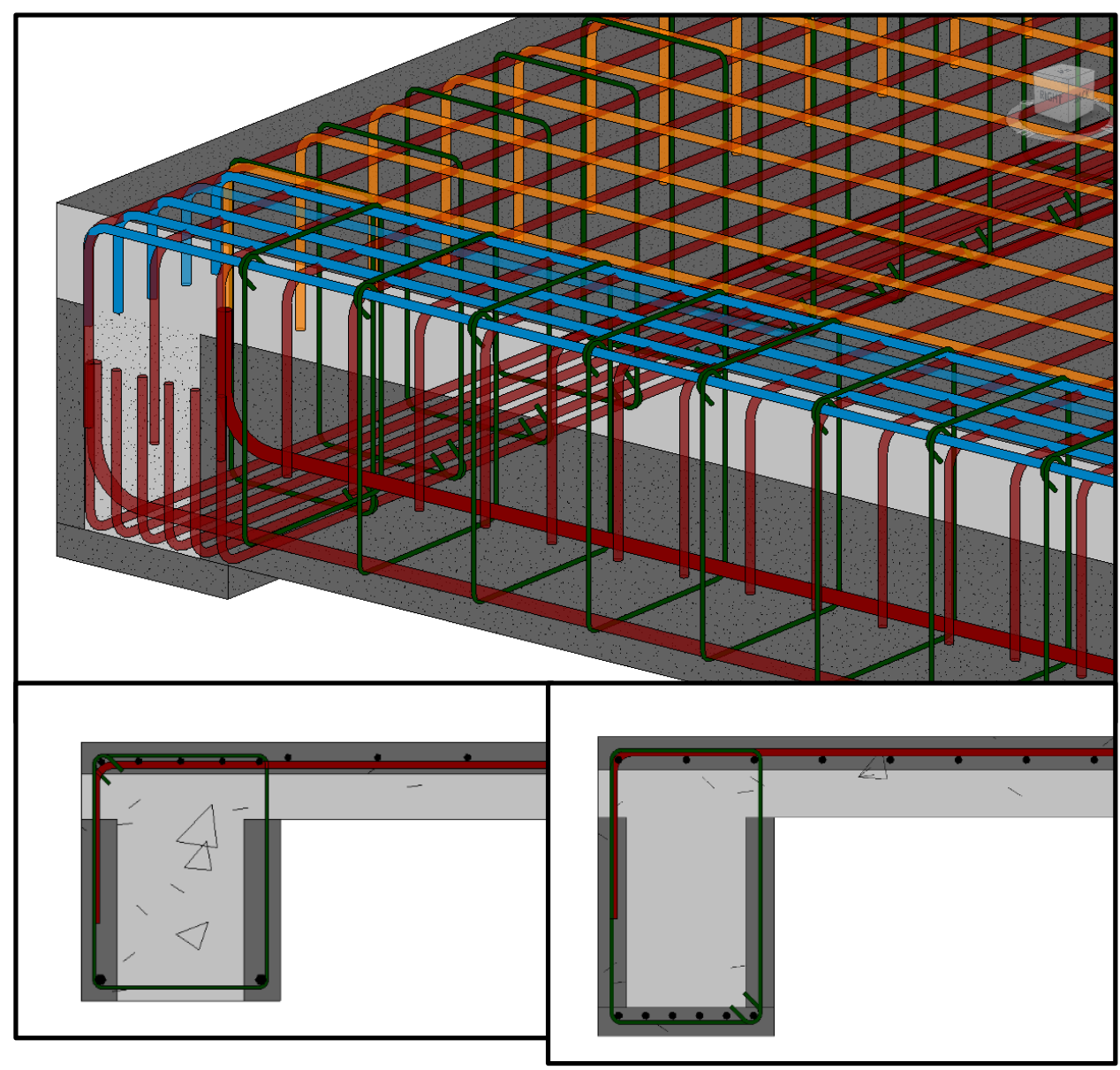

Reforço

\section{Existente}

Figura 4: Armaduras de reforço e ligação entre os elementos novos e os existentes.

\section{Edifício Braamcamp em Lisboa}

Este edifício, construído na década de 50 e localizado na Rua Braamcamp em Lisboa, já foi anteriormente alvo de uma intervenção de forma a adaptá-lo a albergar escritórios, estando, no entanto, no momento da realização deste artigo, sem qualquer utilização.

Tendo em vista a utilização do edifício para fins habitacionais, foi solicitada a realização de um projeto de reabilitação estrutural, pelo que a empresa teve acesso a plantas de arquitetura e estruturais em papel, e levantamentos de arquitetura em formato digital editável 2D que serviram de base para criar um modelo BIM de estruturas.

O modelo BIM permitiu a atualização do projeto mantendo toda a informação do modelo antigo. Neste tipo de intervenção há sempre a preocupação de tentar manter o existente, não só por razões de património, mas também por razões de sustentabilidade dos materiais. Por essa razão optou-se por um reforço que se mostrou economicamente viável.

Desta forma foi possível criar um modelo que inclui a informação relativa a cada etapa e fase do processo construtivo. Para esse efeito foi concebido um modelo de estruturas do edifício existente, antes da intervenção de reabilitação, sendo a partir deste acrescentadas todas as atualizações e alterações, obtendo assim um modelo abrangente de todo o processo. 
Para que tal seja possível, é necessário que o projetista, aquando da conceção do projeto, tenha o cuidado, para todos os objetos do modelo, de designar a fase em que estes aparecem em obra, seja a fase de adicionada aquando do reforço seja a sua própria demolição aquando da construção (Ver Figura 5).

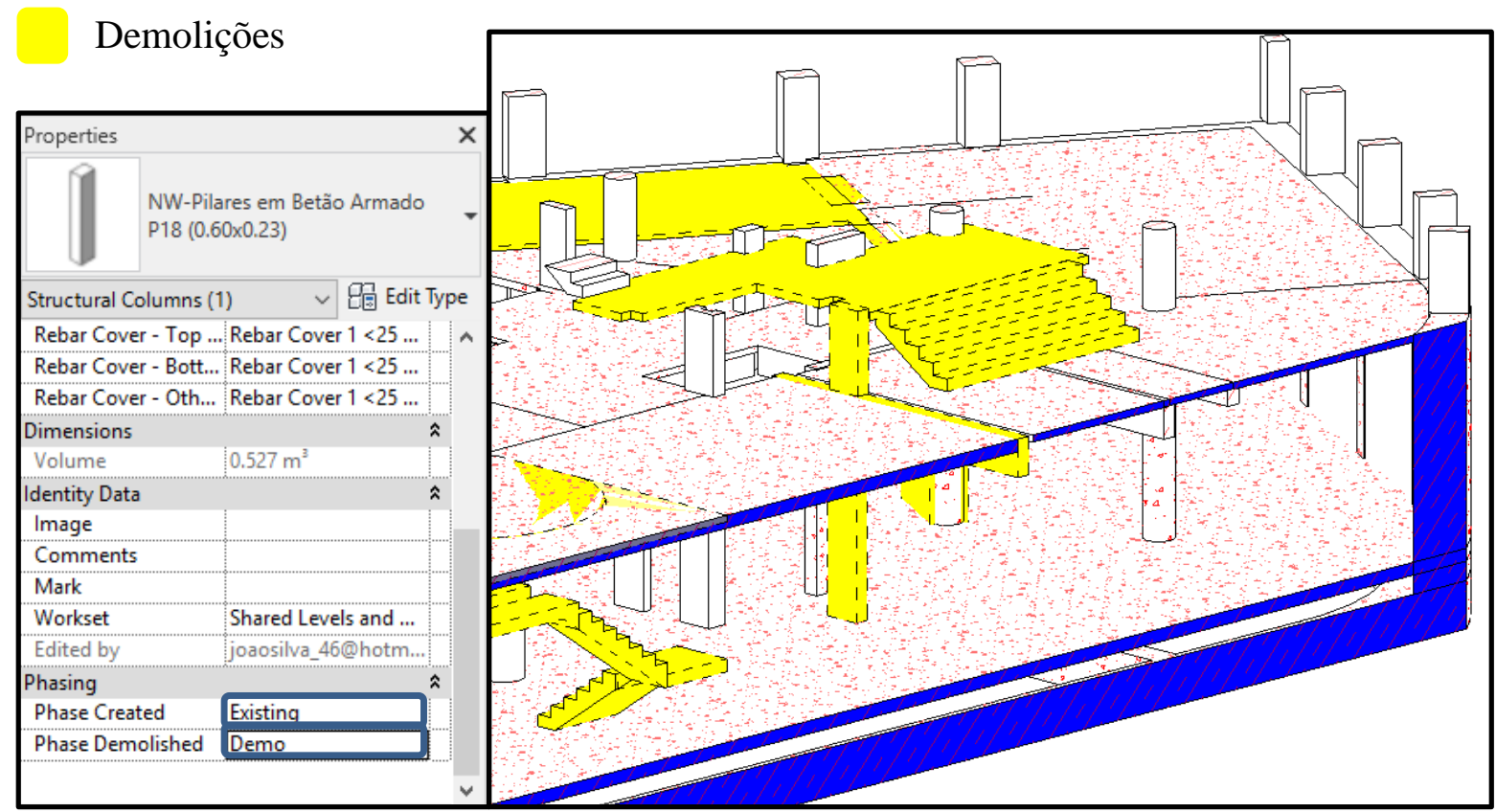

Figura 5: Fase de demolições no faseamento construtivo (Piso -1 e Piso 0).

Durante a execução do projeto, foi necessário realizar a ligação entre o software onde foi concebido o modelo 3D da estrutura e o software de cálculo. Para esse efeito, exportou-se o modelo para o software de cálculo, onde foi avaliada a capacidade estrutural do edifício de acordo com os novos requisitos de utilização, o tipo de materiais constituintes da estrutura e o estado de conservação da mesma.

Depois dessa avaliação, foram adicionados alguns elementos estruturais novos, demolidos outros que entravam em conflito com a nova arquitetura e calculados alguns reforços estruturais necessários, de acordo com a avaliação efetuada.

Após esta etapa, adicionaram-se todas as alterações ao modelo inicial, originando um modelo final com toda a informação relativa a todo o processo de reabilitação estrutural.

A figura 6 mostra alguns dos reforços que foram aplicados à estrutura como encamisamentos de pilares em betão armado e um reforço de $5 \mathrm{~cm}$ na laje existente. 
Encamisamentos

Novos elementos

Estrutura existente

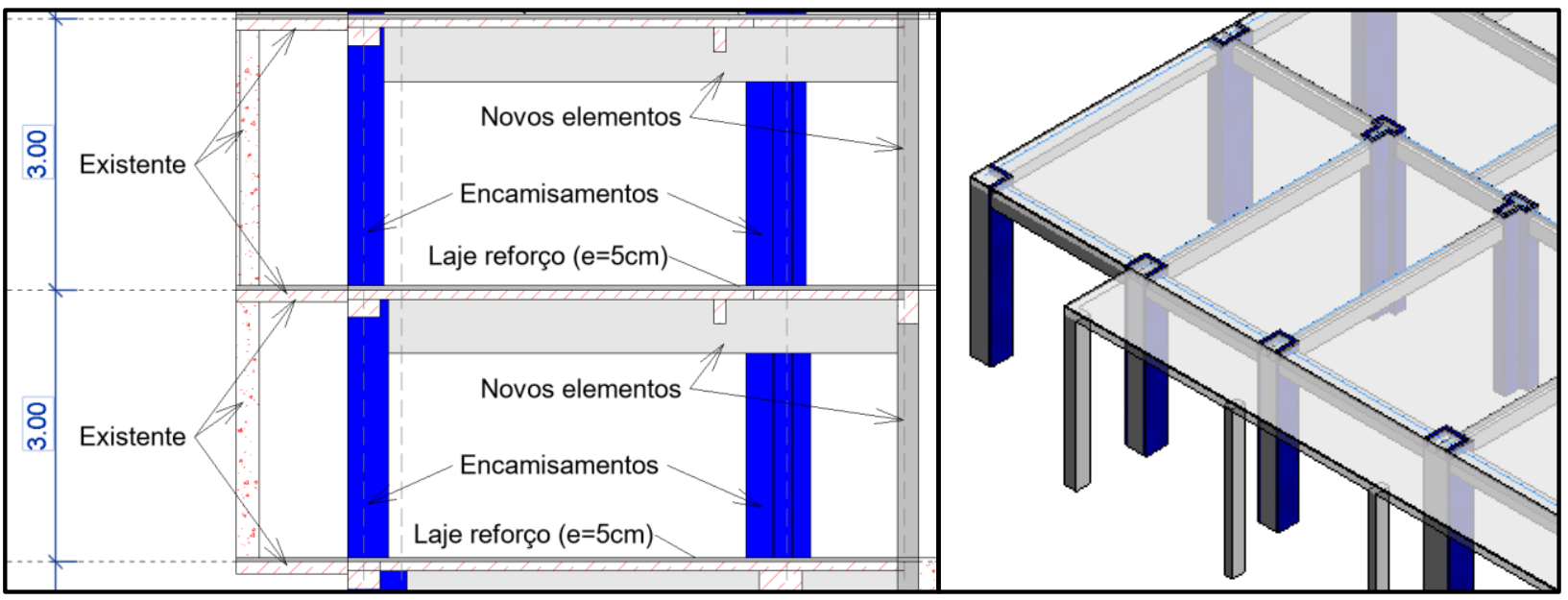

Figura 6: Reforços de laje e encamisamento de pilares (esquerda) e novos elementos estruturais ao nível da cobertura (direita).

\section{Conclusão}

Em Portugal vive-se atualmente um momento em que grande parte das intervenções da indústria da construção são reabilitações no património existente. A necessidade de catalogar e identificar a informação do espaço construído leva os intervenientes a tentar usar o modelo da informação nestas reabilitações em que parte da informação corresponde ao existente, outra parte é aquilo que se vai demolir ou substituir e uma outra parte relativamente ao que se vai efetivamente construir de novo.

No presente artigo foram mostrados dois casos de estudo de reabilitação, onde se recorreu à modelação BIM com extração de vários usos dos modelos. Foram demonstradas várias particularidades relacionadas com aspetos específicos dos projetos de reabilitação, nomeadamente a reconstituição parcial de um projeto de arquitetura em 3D para servir de base ao de estruturas, o que representou vários desafios ao nível do levantamento e da compreensão do projeto de arquitetura que não estavam resolvidos em formato 2D. Esse processo permitiu que o modelo fosse posteriormente usado no contexto da arquitetura e em comunicação com o cliente. No primeiro caso de estudo o encamisamento e as armaduras de reforço foram modelados explicitamente com sucesso, demonstrando que estas técnicas de reforço são viáveis no contexto BIM.

Adicionalmente num segundo caso de estudo foi testada a possibilidade de criteriosamente acrescentar informação aos elementos sobre as respetivas fases, sendo também feita uma partilha de informação entre os softwares utilizados na conceção do modelo BIM, nomeadamente o de modelação 3D e o de cálculo estrutural de forma a avaliar a capacidade estrutural da estrutura de acordo com os novos requisitos de utilização. Desta forma obteve-se 
um modelo global com toda a informação necessária para caracterizar o processo evolutivo da obra.

Pode constatar-se que muito está ainda por fazer nesta área mas a falta de objetos específicos das obras de reabilitação bem como o cuidado na modelação do faseamento das diversas intervenções são alguns dos fatores a que se deve dar atenção prioritária.

\section{Referências}

[1] C. Eastman, P. Teicholz, R. Sacks, K. Liston, "BIM Handbook A guide to Building information Modeling for Owner, Manager, Designers, Engineers, and Contractors." ISBN 9780470541371, Wiley, 2011

[2] E. Macedo, J.C. Lino, F. Reis, J.P. Couto, "Gestão de ativos num projeto de reabilitação urbanística com recurso a metodologias BIM”, $2^{\circ}$ Congresso Português de Building Information Modelling - Lisboa, Portugal, 2018

[3] J.C. Lino, M. Azenha, P. Lourenço, "Integração da metodologia BIM na engenharia de estruturas" - BE2012-Encontro Nacional Betão Estrutural, 2012

[4] J. Lopes, M. J. F. Silva, F. F. S. Pinho, P. Couto, "Utilização da metodologia BIM no apoio à reabilitação funcional de um edifício", $2^{\circ}$ Congresso Português de Building Information Modelling - Lisboa, Portugal, 2018

[5] M. Campos, "Reabilitação dos edificios singulares da companhia de fiação de crestuma", $2^{\circ}$ Congresso Português de Building Information Modelling - Lisboa, Portugal, 2018

[6] B. Baptista, G. Inocentes, M. Encarnação, "A recolha de dados para integração em BIM", $2^{\circ}$ Congresso Português de Building Information Modelling - Lisboa, Portugal, 2018

[7] R. Giollo, M. J. F. Silva, P. Couto, "Reabilitação de um edifício público: contributo para a interoperabilidade entre BIM e pronic", $1^{\circ}$ Congresso Português de Building Information Modelling - Guimarães, Portugal, 2016 